10-19-2018

\title{
Mario Kart 8: A Case Study In Total Internal Reflection
}

\author{
Robert Polak \\ Loyola University Chicago, rpolak@luc.edu \\ Vincent Acuesta \\ Jonathon Cirone \\ Matthew B. Conway \\ Joseph Summers
}

See next page for additional authors

Follow this and additional works at: https://ecommons.luc.edu/physics_facpubs

Part of the Physics Commons

\section{Recommended Citation}

Polak, Robert; Acuesta, Vincent; Cirone, Jonathon; Conway, Matthew B.; Summers, Joseph; and Tinawi, Lana, "Mario Kart 8: A Case Study In Total Internal Reflection" (2018). Physics: Faculty Publications and Other Works. 51.

https://ecommons.luc.edu/physics_facpubs/51

This Article is brought to you for free and open access by the Faculty Publications and Other Works by Department at Loyola eCommons. It has been accepted for inclusion in Physics: Faculty Publications and Other Works by an authorized administrator of Loyola eCommons. For more information, please contact ecommons@luc.edu.

\section{(c) (i) $\Theta$}

This work is licensed under a Creative Commons Attribution-Noncommercial-No Derivative Works 3.0 License. (c) AIP Publishing, 2018. 


\section{Authors}

Robert Polak, Vincent Acuesta, Jonathon Cirone, Matthew B. Conway, Joseph Summers, and Lana Tinawi 


\section{Mario Kart 8: A case study in total internal reflection}

\author{
Robert Polak, Vincent Acuesta, Jonathon Cirone, \\ Matthew B. Conway, Joseph Summers, and Lana \\ Tinawi, Loyola University Chicago, Chicago, IL
}

$\mathrm{N}_{\mathrm{tin}}^{\mathrm{i}}$ intendo's Mario Kart 8 features several underwater tracks, allowing players the opportunity to race through aquatic environments. One of the courses, titled "Water Park," features a scene where the player surfaces from water by driving up a ramp. From the player's perspective, an unrefracted image of a Ferris wheel and two trees is present above the water line as shown in Fig. $1{ }^{1}$ Of course, this view ignores the

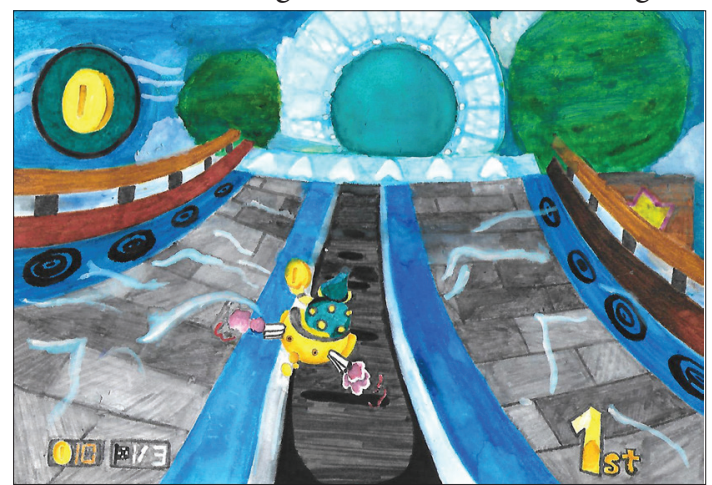

Fig. 1. This is a replication of a screenshot of the racer in the Water Park course. The racer is currently underwater and going up a ramp. He is viewing objects above the waterline such as the Ferris wheel and the trees. Notice the only distinction for objects above the water line is a marginally visible blue hue.

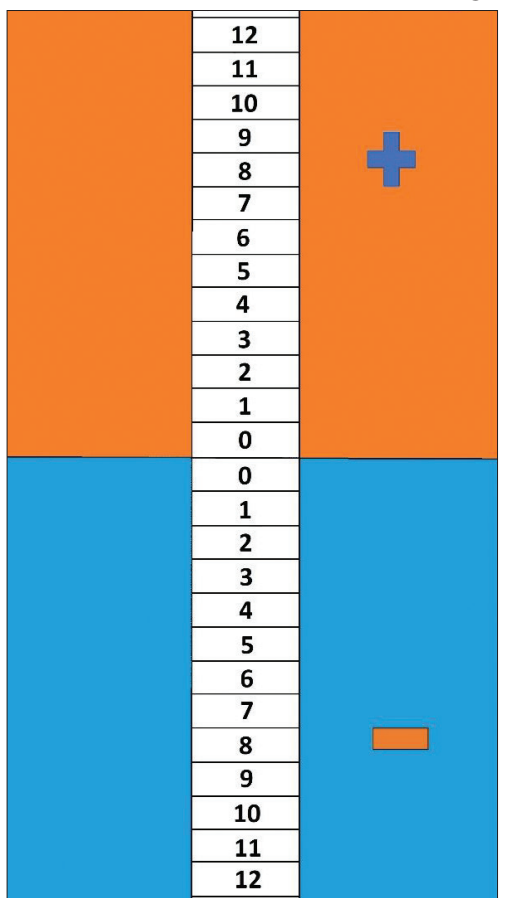

index of refraction difference of water and air; the only distinction players can make between the two environments is a marginally visible blue hue to the features above the water line.

After completing my lectures on optics to an introductory physics class for physics majors, the students were asked to draw what they thought a player would see if they applied the physics they had just learned. After working in groups for 10 minutes, students presented their results-none had the correct answer. Instead of focusing on the proper application of Snell's law, we found the students instead focused on relative size of the objects in the image and whether they would appear closer or farther away than their actual position. Only one group realized that Snell's law would affect the relative vertical position.

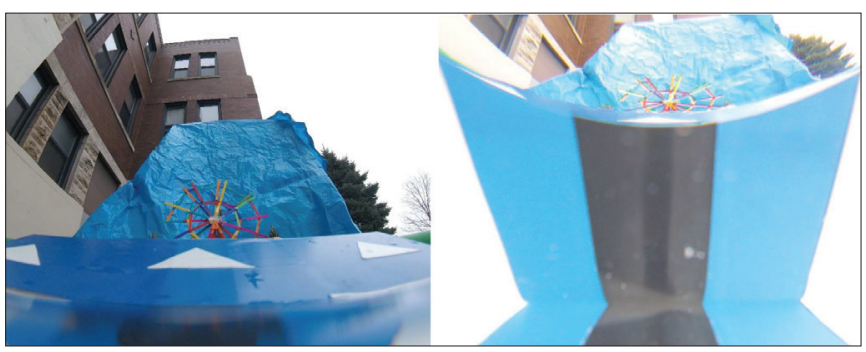

Fig. 3. This figure shows the difference between what a racer sees in the game and what the racer should see if physics is properly applied. We take the image on a ramp, with the left image showimg an image taken with no water present and similar to what the player would see in the actual game. The right image shows an image taken from the ramp from the same position, but with water placed such that the camera is below the water line. Notice that the effects of Snell's law and total internal reflection are apparent in the right image and is indicative of what the player should see.

We decided to demonstrate, in the classroom, the racer's perspective with Snell's law applied as he is coming out of the water. We used a laminated page of the image shown in Fig. 2. This page was affixed to one end of a half-filled fish tank with the divide between the red portion above the water line and the blue portion below the water line. The numbers in the middle give the distance from the water-air interface in centimeters. We submerged a Go Pro HERO4 Session camera in the water. Using the program Camera Suite ${ }^{2}$ on a laptop computer, we were able to broadcast a live preview of the camera feed to the class. Despite the camera being underwater, the live preview worked fairly well, even though the laptop would occasionally lose the camera signal. With this perspective, the students were able to "discover" the effects of Snell's law and total internal reflection with observational analysis. The students could then visualize what the racer would see if hurtling up the underwater ramp. Students were then asked to, once again, produce what they believed the racer would see on the Water Park course-overwhelming success was found at this point. We then compared the results with the examples given in Fig. 3, where we simulated the actual racing environment. 


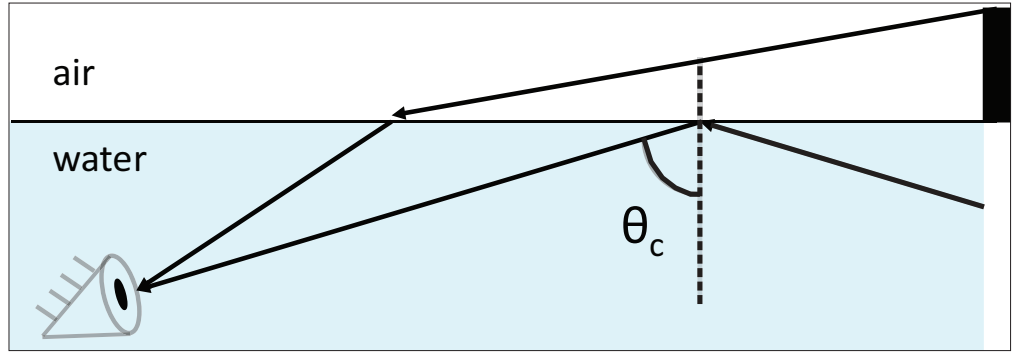

Fig. 4. A ray diagram of the view that the observer would have. The object above the water line (shown as a rectangular block) will appear higher than the observer would expect otherwise, while rays below the water line may reflect internally to be seen by the observer.

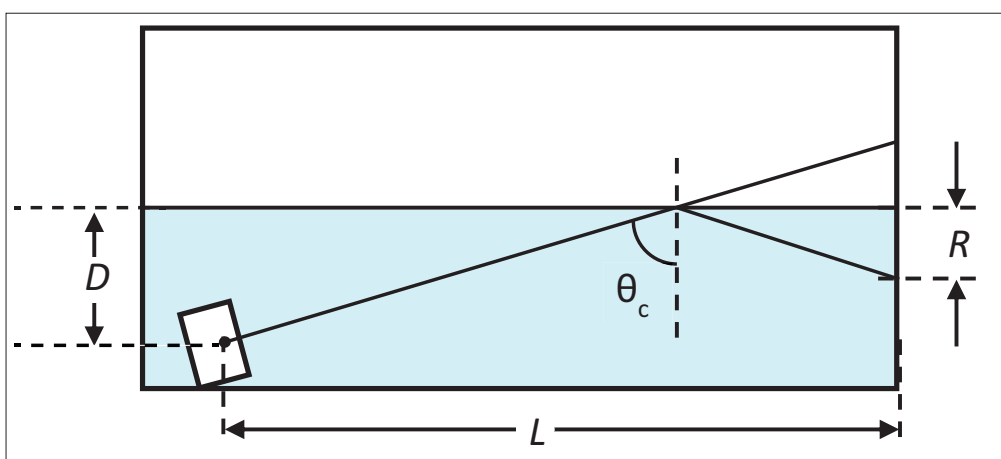

Fig. 6. The camera is tilted at an angle, seeing light transmitted from above the water line as well as the total internal reflection. By using the image to determine the distance below the surface that is totally internally reflected $(R)$, we can determine the critical angle $\left(\theta_{C}\right)$ by measuring the vertical distance from the camera's nodal point, marked by a dark circle on the rectangular camera to the water line $(D)$ and the horizontal distance to the laminated sheet $(L)$.

Students can be asked to create a ray diagram showing light rays at the critical angle reflecting off the surface while those coming from above the water line would appear higher in the observer's point of view as shown in Fig. 4.

After demonstrating they could apply their physics knowledge qualitatively, the class was then challenged to determine the index of refraction of water using the images from the GoPro camera. The method we proposed began by placing the camera at a tilted angle on the bottom of the tank, such that it could capture the image of the transition from total internal reflection to transmission with the interface at roughly the center of the image. Using this image, we determined the vertical distance at the edge of the tank that was totally internally reflected, $R$ as shown in Fig. 5 .

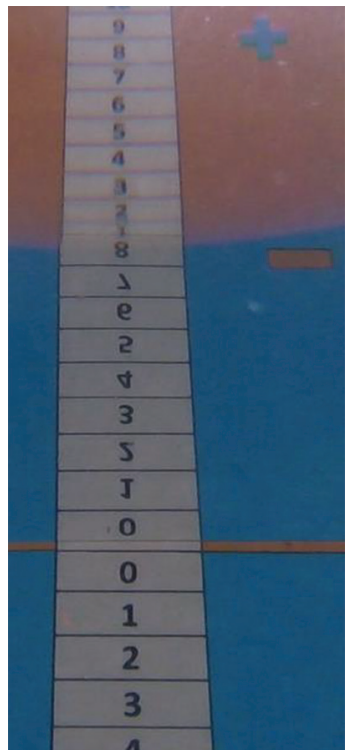

Fig. 5. The image of the laminated sheet shows both the total internal reflection and the effects of Snell's law. From this, we can determine the depth of the laminated image that is totally internally reflected using the ruler on the sheet. In this case, it is approximately $8.5 \mathrm{~cm}$. measured values of $D=9.5 \mathrm{~cm}$ and $L=20.0 \mathrm{~cm}$, the students found the critical angle and the index of refraction of water to be $48^{\circ}$ and 1.35 , respectively. The accepted value of the index of refraction of water is 1.33.

We found that using this demonstration and experiment in class over a 100-minute period allowed us to show how to properly apply Snell's law and total internal reflection using a commonly played video game as motivation.

\section{References}

1. Artist rendition by Emma M. Mattix-Wand.

2. H. Meyer, Camera Suite (Austria, 2018). The software is available at www.camerasuite.org. 